\title{
Biaxially curved glass with large radii-determination of strength using the coaxial double ring test
}

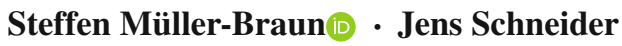

Received: 4 April 2017 / Accepted: 27 September 2017 / Published online: 23 October 2017

(C) Springer International Publishing AG 2017

\begin{abstract}
The coaxial double ring test is used for determining the surface strength of flat glass e.g. as it is described in existing standards. The main idea of this test setup is to generate a defined area of surface tensile stress, which is uniform in all directions within the load ring. Thus, the orientation of surface flaws does not influence the test results. Furthermore, the defined area with uniform stress allows a statistical evaluation with regard to the flaw distribution and therefore a prediction for deviating area sizes is possible. For biaxially curved glass, the generation of such an area of uniform tensile stress is not easily possible in a test setup. However, for large radii of curvature and low glass thicknesses it is possible to flatten the specimen during the test and to generate an area of uniform tensile stress with increasing load. This contribution shows under which geometrical conditions the coaxial double ring test can also be used for biaxially curved glass.
\end{abstract}

Keywords Curved glass - Coaxial double ring test - Bending strength of glass - Annealed glass · Spherically curved glass

\footnotetext{
S. Müller-Braun $(\varangle) \cdot J$. Schneider Institute of Structural Mechanics and Design, Technische Universität Darmstadt, Franziska-Braun-Straße 3, 64287 Darmstadt, Germany e-mail: mueller-braun@ismd.tu-darmstadt.de

J. Schneider

e-mail: schneider@ismd.tu-darmstadt.de
}

\section{Introduction}

Freely shaped geometries are becoming more and more an issue in the building sector's design process through better possibilities in the area of computer-aided modelling and design. In facades, curved glass plays an important role in this development. The skylights of the Städel Museum in Frankfurt (Germany), for example, consist of spherically curved glass with radii of curvature between 18 and $30 \mathrm{~m}$ (Fig. 1a). In the automotive industry, curved glass, for example in windshields (Fig 1b) with radii of curvature down to 1 , $5 \mathrm{~m}$, has also been used for many years. The gravity bending method and the press bending method are the most common manufacturing techniques for hot-bent glass. However, a standardized test method for determination of the curved glass strength does not exist. The four-point bending test is a convenient method to determine the strength of cylindrically bent glass. However, the stressed edge does have an influence on the test results in this setup. For cylindrically curved glass, basic knowledge and recommendations regarding tolerances and testing possibilities are also available (Ensslen et al. 2010; Bundesverband Flachglas 2011).

Testing the strength of multiaxially curved glass is much more difficult. The coaxial double ring test (CDR) is a rotationally symmetrical experimental setup which is particularly suitable for testing brittle materials, in which the specimen should be ideally plane. Pećanac et al. (2011) examined spherically curved solid oxide fuel cells (SOFCs) by using the CDR. The study 



Fig. 1 Skylights at the Städel Museum in Frankfurt (Germany) (a) and a typical automotive windshield (b)
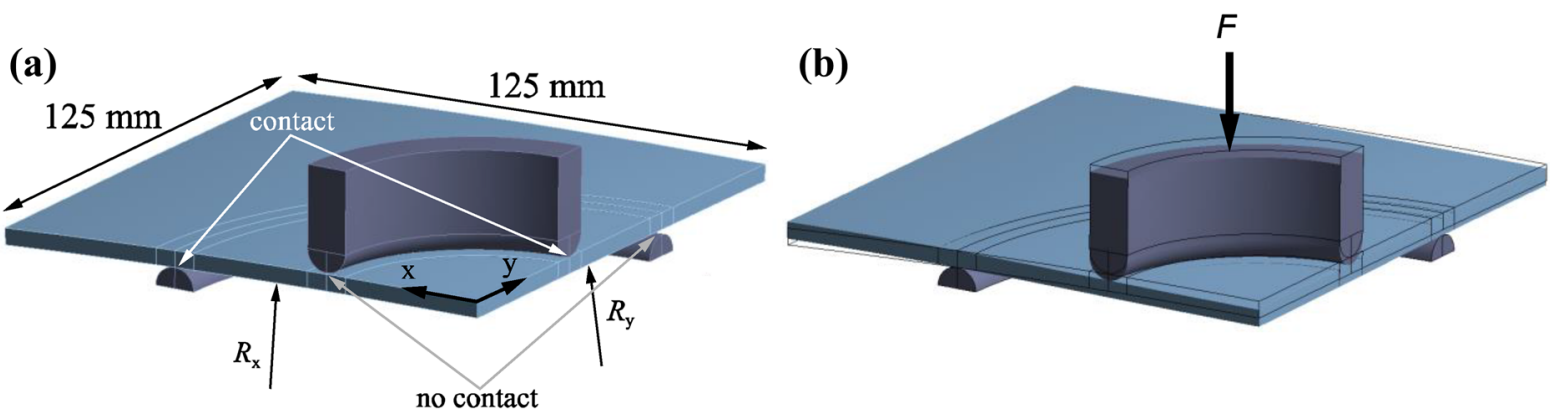

Fig. 2 Biaxially curved glass with large radii $R_{\mathrm{x}}$ and $R_{\mathrm{y}}$, which is flattened during the experiment and thus completely adapts to the load ring and support ring, without load (a), loaded (b)

on this very thin material (the thickness of SOFCs is about $310 \mu \mathrm{m}$ ) were carried out on a very small experimental scale of the CDR with a diameter of the load ring of $9 \mathrm{~mm}$, a diameter of the support ring of $19 \mathrm{~mm}$ and a sample diameter of $25,1 \mathrm{~mm}$. It was found that similar stress distributions as for flat specimens can be obtained from this experimental setup. However, restrictions on the smallest radius of curvature and on the load level are given. The advantage of the spherically curved glass is that it always has full geometrical contact with the support ring and the load ring of the CDR. This is not the case with multiaxially bent glass. Figure 2 shows a quarter model of the test setup, which was developed with a diameter of the load ring of $80 \mathrm{~mm}$, a diameter of the support ring of $160 \mathrm{~mm}$ and a square sample with a side length of $250 \mathrm{~mm}$ and a thickness of $4 \mathrm{~mm}$ as this represents a common glass thickness. In addition, the shown specimen is biaxially curved with different radii $R_{\mathrm{x}}$ and $R_{\mathrm{y}}$. In Fig. 2a, the setup without load is shown. Only the specimen on the sectional plane, facing the viewer touches the support ring, while the load ring on this plane has no contact with the specimen. The loaded specimen is shown in Fig. 2b. In the loaded state, the specimen is fully in contact with the support ring and the load ring. With an increasing load, the stress profile of a flat test specimen superimposes the stress profile resulting from the aforementioned structurally non-linear behaviour, which has ceased until the full contact. If the stress profile in the moment of the first complete contact is of lower significance, the CDR can also be used for biaxially curved glass.

Gulati et al. (2000) examined laminated and curved windshields with respect to their breakage stress, using the coaxial double ring test. Here, the breakage stresses were determined by means of strain gauge rosettes at the centre of the specimen. The stress profile within the load ring was assessed by means of further strain gauges at a distance of $19 \mathrm{~mm}$ from the centre point, as well as directly under the load ring. Thus, differences of $5 \%$ in the major axis and $30-50 \%$ in the minor axis were obtained, with stress values in the minor axis reaching only $50 \%$ compared to the values obtained from the major axis. Therefore, stresses in the major axis are responsible for breakage. 
Fig. 3 Geometry of the coaxial double ring test setup

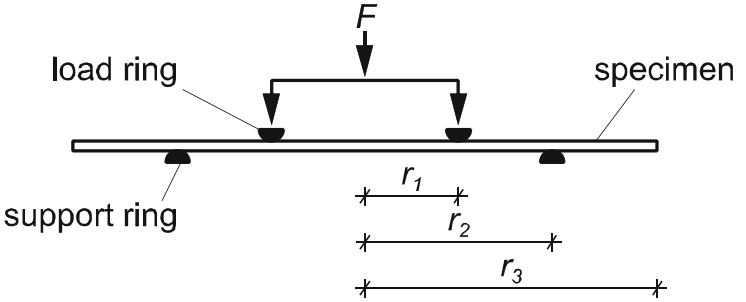

In this paper, it is systematically examined, in which range the considered experimental setup for curved glass fulfils the actual intention of the double-ring bending test for flat glass. The main focus lays on the influence of different radii of curvature on the generation of a uniform stress field within the load ring. By parameter studies, limitations are discussed in which the CDR can be appropriately used for curved glasses.

\section{Methods}

\subsection{The coaxial double ring test}

The basis of the investigations undertaken is the coaxial double ring test. This setup is shown in sectional view in Fig. 3. Although the load ring and the support ring are rotationally symmetrical, the specimen can also be a square in accordance with EN 1288-1 (2000). This has practical reasons, since square specimens are easier to fabricate. For the complete rotationally symmetrical setup, the analytical solution for the radial stresses $\sigma_{r}$ and the tangential stresses $\sigma_{t}$ on the surface enclosed by the load ring on the tensile side of the specimen according to Kirchhoff's plate theory is given in Eq. (1). The deflection of the specimen at the centre can be calculated with Eq. (2).

$$
\begin{aligned}
\sigma_{r}= & \sigma_{t} \\
= & \frac{3 \cdot F \cdot(1+\mu)}{2 \cdot \pi \cdot h^{2}} \cdot\left[\ln \frac{r_{2}}{r_{1}}+\frac{(1-\mu)}{(1+\mu)} \cdot \frac{\left(r_{2}^{2}-r_{1}^{2}\right)}{2 \cdot r_{3}^{2}}\right] \\
w= & \frac{3 \cdot F \cdot\left(1-\mu^{2}\right)}{2 \cdot \pi \cdot E \cdot h^{3}} \\
& \cdot\left[r_{2}^{2} \cdot\left(1+\frac{(1-\mu)}{\left(1+\mu^{2}\right)} \cdot \frac{\left(r_{2}^{2}-r_{1}^{2}\right)}{2 \cdot r_{3}^{2}}\right)\right. \\
& \left.-r_{1}^{2} \cdot\left(1+\ln \frac{r_{2}}{r_{1}}\right)\right]
\end{aligned}
$$

If a square specimen is used, the mean value of the circumcircle and the inner circle according to Eq. (3) can be used with a very good approximation for the radius $r_{3}$. Where $L$ denotes the edge length of the square sample.

$r_{3}=\frac{(1+\sqrt{2})}{2} \cdot \frac{L}{2}$

This experimental setup is very applicable to glass because the stress field at the surface of the specimen within the load ring is constant and regardless of the direction. The strength of glass is determined by barely or not visually perceptible flaws at the surface. These microcracks will show a failure in mode I of fracture mechanics, which means, that tensile stresses perpendicular to the crack will lead to failure. For this reason, the orientation of the microcracks is important, since stresses acting perpendicular to the edge of the crack cause the greatest stress intensity. An additional point for consideration is that microcracks are randomly distributed on the surface. By means of a uniformly loaded reference surface, a statistical interpretation can thus be made depending on the loaded surface size. Assuming a statistical adaptation of the breaking strengths to a two-parameter Weibull distribution, the breakage strengths can be adapted to deviating surface sizes of tensile stress according to Eq. (4), whereby the same failure probability applies (Overend 2010; Schneider et al. 2016). Here $\sigma_{f, A_{i}}$ is the breaking strength associated with a defined reference surface $A_{i}$, and $\lambda$ is the shape parameter of the Weibull distribution.

$\frac{\sigma_{f, A_{1}}}{\sigma_{f, A_{0}}}=\left(\frac{A_{0}}{A_{1}}\right)^{\frac{1}{\lambda}}$

Based on this, the principle of effective stresses can be used to evaluate non-uniform areas of tensile stress. For this purpose, a stress value is calculated by means of integration over the surface area, which has the same breakage probability as the non-uniform stress distribution acting on the surface (Beason et al. 1984). However, for such an evaluation, the exact stress profile as 


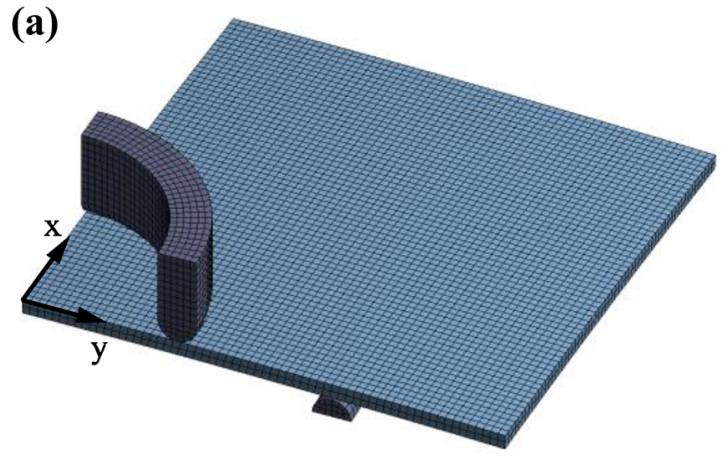

Fig. 4 FE model with mesh (a) and defined contact areas (b)

well as the shape parameter $\lambda$ of the Weibull distribution must be known.

Dimensions of the CDR for testing glass, which is going to be used in the building sector, are given in EN 12882. Here, the area of equibiaxial tensile stress is $240.000 \mathrm{~mm}^{2}$. This results in large radii of the load ring and the support ring. Because of these large dimensions, the resulting deformations in this test setup are very high, whereby the behaviour is strongly geometrically non-linear. According to the standard, this nonlinear behaviour is to be counteracted by air pressure, applied onto the glass pane within the loading ring. This additional step results in a complex setup which may be vulnerable to application errors. On the basis of the aforementioned principle of effective stresses, Pisano et al. (2015) proposes a smaller setup of the CDR in which no air pressure is necessary. However, even here there are geometric non-linear effects that lead to a nonuniform stress profile. These non-linear effects are taken into account here with correction factors depending on the specimen thickness.

To avoid a large influence of geometrical nonlinearities for typical glass thicknesses architectural and automotive glass, a CDR with the dimensions of $r_{1}=40 \mathrm{~mm}$ and $r_{2}=80 \mathrm{~mm}$ was chosen. The edge length of the specimen was chosen to $L=250 \mathrm{~mm}$ and the thickness of the glass pane was set to $4 \mathrm{~mm}$. The characteristic tensile strength of float glass as given in standards (EN 572-1 2012) is $45 \mathrm{MPa}$, so that with the selected dimensions and for the relevant stress levels of about 40-140 MPa, geometrically non-linear effects in the test procedure with planar glass only have a larger influence for higher loads. In addition, it is useful for practical reasons (b)

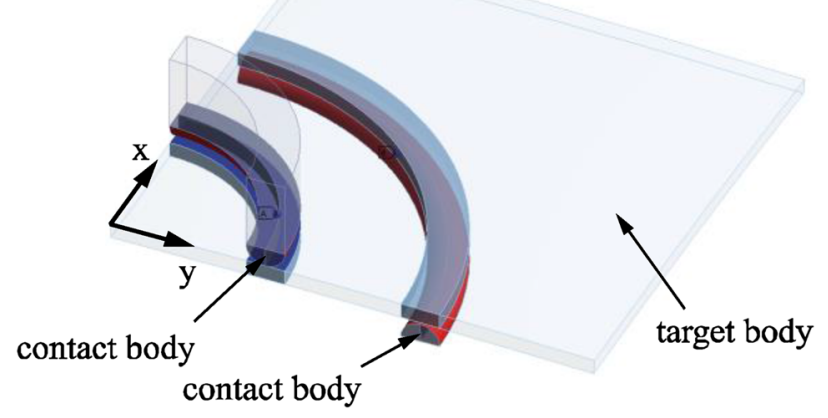

to allow deviations of the stresses within the load ring in a certain range. EN 1288-1 (2000) specifies a limit value of $2 \%$. The transfer of the results to larger areas according to Eq. (4) is also possible here.

\subsection{Finite-element model}

An FE model was developed in the commercial FE Software ANSYS (version 17.2) in order to conduct the aforementioned investigations. The radii $R_{\mathrm{x}}$ and $R_{\mathrm{y}}$, the thickness of the biaxially curved glass and the applied load were configurated as variables. Furthermore, the double symmetrically properties of the test setup were considered. In Fig. 4 the model including the mesh and the contact surfaces are shown. Three-dimensional 20-node structural solid Elements SOLID186 with full integration were used. The element size of $2 \mathrm{~mm}$ has been determined during a mesh sensitivity study. In Fig. 5, the principal tensile stress at the lower side of the specimen in the area of the load ring is shown. It was found that element sizes smaller than $2 \mathrm{~mm}$ do not lead to any significant increase in stresses. The contacts were modelled frictionless. Hence, it is important to avoid effects of friction for the experimental setup, e.g. by using thin PTFE interlayers. The load ring and support ring were defined as contact bodies and the glass element was defined as target body. In addition, element nodes were defined at the vertex of the rings. Augmented Lagrange formulation was used for the contact and the detection method was set to nodal-normal to target. The pinball radius, within the contact will find the target, was set to $1 \mathrm{~mm}$. In the case of flat glass and spherically curved glass, the contact status at the begin- 
Fig. 5 Principal stress $\sigma_{1}$ at the lower surface along the $\mathrm{x}$-axis in the area of the load ring for different element sizes at a load level of $3232 \mathrm{~N}, R_{\mathrm{x}}=2000 \mathrm{~mm}$, $R_{\mathrm{y}}=3000 \mathrm{~mm}$, thickness of glass $t=4 \mathrm{~mm}$

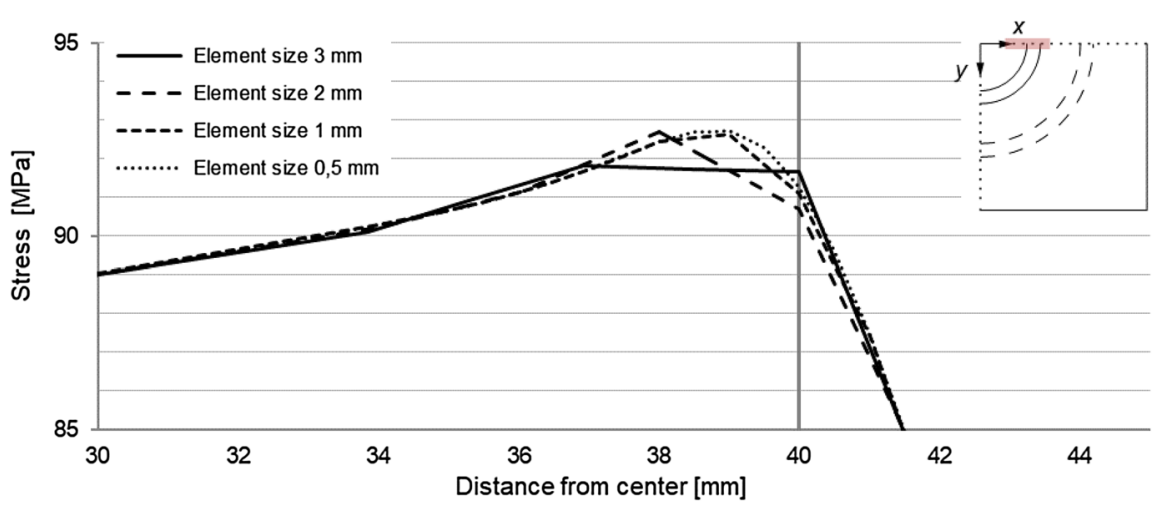

(a)



(b)

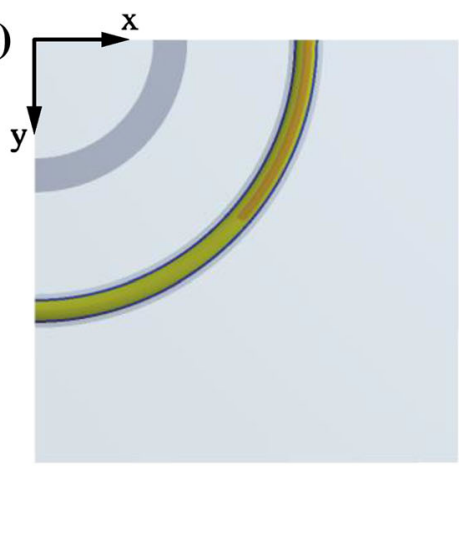

(c)

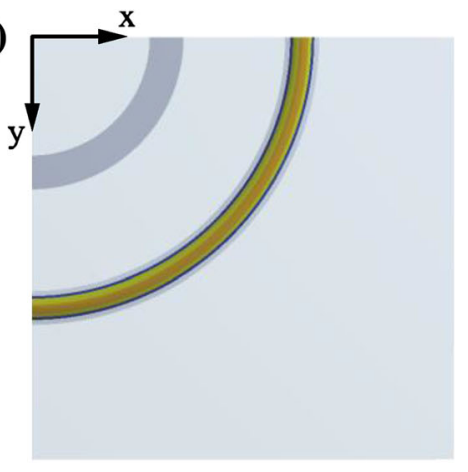

Fig. 6 Changing of the contact status of the support ring during the simulation at the load levels $p=0,1$ (a), $p=0,25$ (b), $p=$ $1(\mathbf{c})$; blue $=$ far away, yellow $=$ close, orange $=$ sliding, radii of curvature of the glass pane: $R_{\mathrm{x}}=2000 \mathrm{~mm} ; R_{\mathrm{y}}=3000 \mathrm{~mm}$, load $p(1)=3232 \mathrm{~N}$ ning of the simulation is sliding over the entire length of the load and support ring. For two different radii of curvature, the contact status changes when the glass is flattened (Fig. 6). In order to respect this structurally non-linear behaviour, the load was applied step by step with at least 20 and a maximum of 50 steps. The initial step width was set to $1 / 50$ of the load.

The material parameters of the glass were set to $\mathrm{E}=70000 \mathrm{MPa}$ and $v=0,23$. The load ring and the support ring were modelled with the material properties of structural steel. The bottom of the support ring was fixed. The load was applied at the entire top surface of the load ring. Furthermore, the load ring was modelled very stiff. This was done because in the case of biaxially curved glass, the load ring touches the glass surface only at two points during the beginning of the simulation. Thus, the addition of material prevents deformation in the load ring due to loading. The radii of the semicircles of the support ring and the load ring were $5 \mathrm{~mm}$.

\section{Results and discussion}

\subsection{Spherically curved glass}

In a first step, spherically curved glass is examined. The radial stresses $\sigma_{r}$ and the tangential stresses $\sigma_{t}$ are shown in Fig. 7 for three different radii at the same load level. All results were generated by FE analyses. The used load level of $1616 \mathrm{~N}$ was chosen by the condition that an analytically determined tensile stress of $f_{k}=$ $45 \mathrm{~N} / \mathrm{mm}^{2}$ occurs. Setting a very large radius in the numerical simulation, the profile of the tensile stress becomes similar to the analytical solution for flat glass. With increasing curvature, two effects occur: On the one hand, the values of the tensile stress within the 
Fig. 7 Radial and tangential stresses $\left(\sigma_{r}\right.$ and $\left.\sigma_{t}\right)$ at a load level of $1616 \mathrm{~N}$ for spherically curved glass at different radii, thickness of glass $t=4 \mathrm{~mm}$

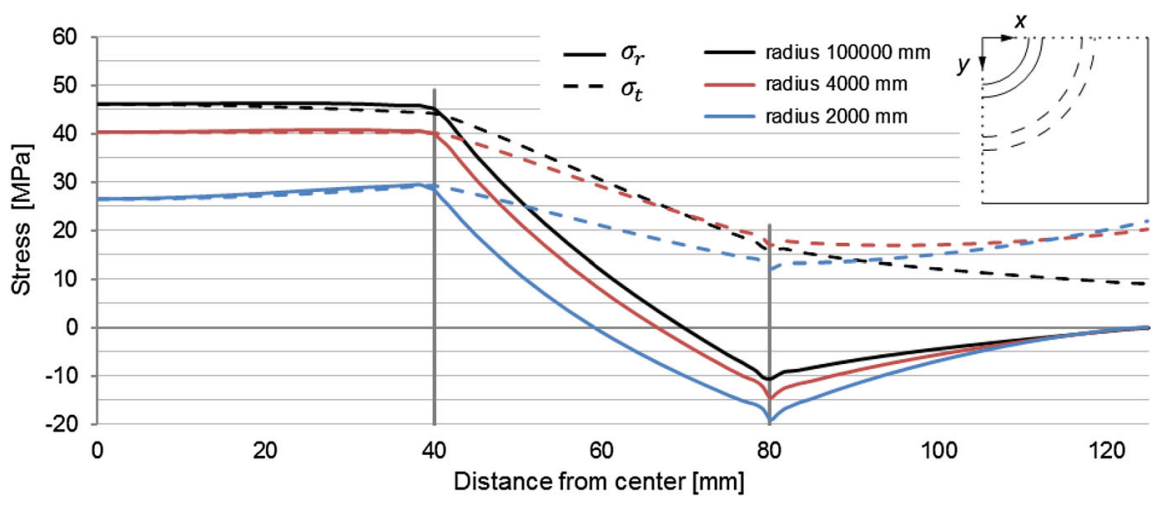

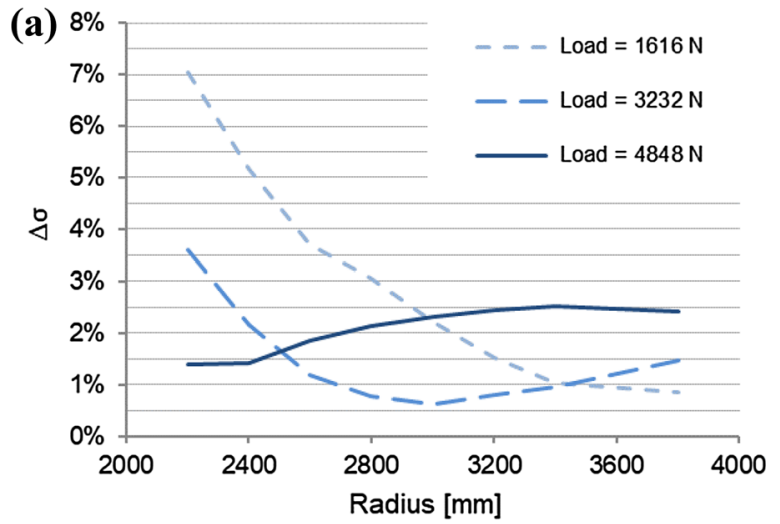

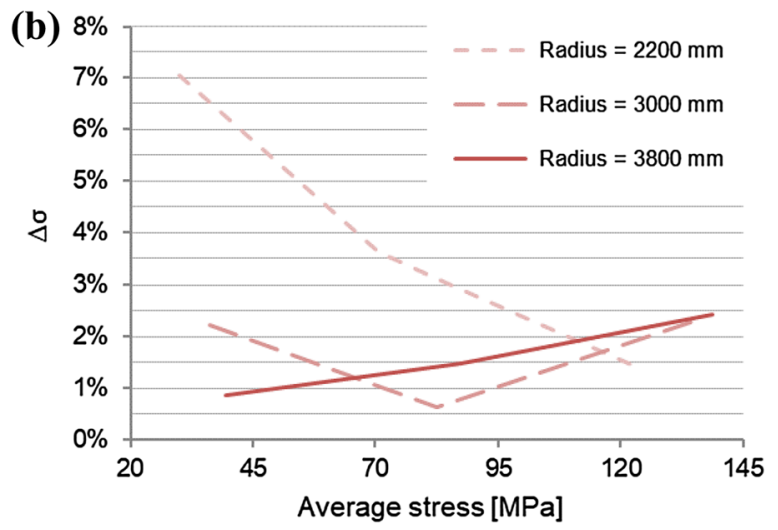

Fig. 8 Stress differences $\Delta \sigma$ as a function of radius and load (a) respectively average stress (b)

load ring are reduced and, on the other hand, the tensile stress differences within the load ring increase.

Based on this, a parameter study was carried out to quantify the relative stress difference $\Delta \sigma$ within the load ring as a function of the radius as well as of the load level. For this, the relative stress difference $\Delta \sigma$ is referred to the highest tensile stress value within the load ring, with no distinction being made between $\sigma_{r}$ and $\sigma_{t}$. It should be noted that for the special case of rotationally symmetrical, spherically curved glass $\sigma_{r}$ and $\sigma_{t}$ are the principal stresses. Hence, the relative stress difference $\Delta \sigma$ can be expressed with Eq. (5), wherein $\sigma_{1}$ and $\sigma_{2}$ are the principal stresses (with $\left.\sigma_{1}>\sigma_{2}\right)$ at the glass surface which is faced to the support ring. Thus both, the difference between the two principal stresses relative to each other, as well as the difference of the principal stresses within the load ring, is considered.

$\Delta \sigma=1-\frac{\min \left(\sigma_{2}(r, \varphi)\right)}{\max \left(\sigma_{1}(r, \varphi)\right)}$ with $0 \leq r \leq r_{1}$
It can be seen in Fig. 8 a, that the relative stress difference $\Delta \sigma$ within the load ring depends both on the radius and on the load level: The flatter the curvature (bigger radius), the lower the load dependency. Thus, it is possible to specify stress ranges for a specific radius in which the differential tensile stresses do not exceed a certain limit. The shown average stress values (Fig. 8b) were calculated with the maximum and minimum values of $\sigma_{r}$ and $\sigma_{t}$. Considering for example a stress range of approx. $40-125 \mathrm{MPa}$ and a radius of $3000 \mathrm{~mm}$ the relative stress differences do not exceed a value of $2 \%$ as it is requested in EN 1288-1 (2000). For smaller radii, a higher load is needed, since the specimen has to be flattened more to generate a homogeneous stress distribution. The load at failure measured in the test must be converted into the breaking stress. As already shown, the correlation between the applied load and the resulting stress is non-linear. The deflection in the centre of the specimen shows the same behaviour. In Fig. 9 it can be seen, that this non-linearity decreases with larger radii. Hence, the analytical solution for the 

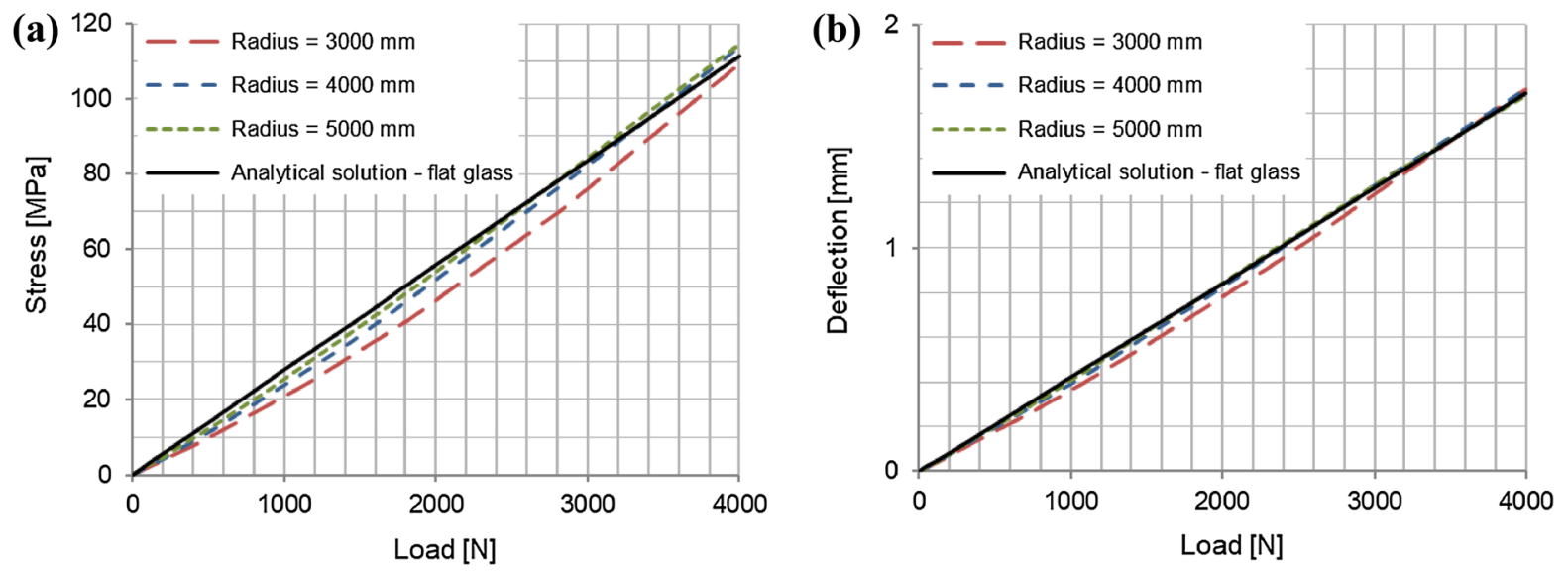

Fig. 9 Radial stress $\sigma_{r}$ (a) and deflection $w$ (b) in the centre as a function of the applied load for different radii, spherically curved glass, thickness of glass $t=4 \mathrm{~mm}$

Fig. 10 Maximum principal tensile stress $\sigma_{1}$, $R_{\mathrm{X}}=2000 \mathrm{~mm}, R_{\mathrm{y}}=$ $10000 \mathrm{~mm}, \mathrm{~F}=3232 \mathrm{kN}$, view from below, thickness of glass $t=4 \mathrm{~mm}$
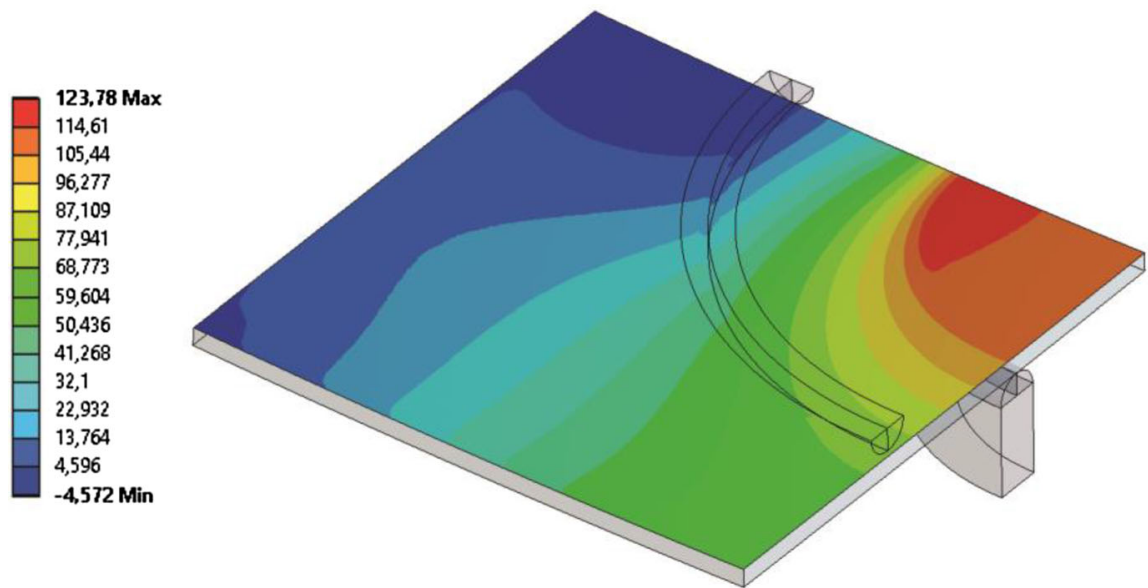

stress and the deflection [Eqs.(1) and (2)] delivers sufficiently accurate results. For smaller radii, the geometrical non-linear behaviour should be respected. Considering for example a spherically curved glass with a thickness of $t=4 \mathrm{~mm}$, a radius of $3000 \mathrm{~mm}$ and breakage load of $2838 \mathrm{~N}$, the strength can be determined to 70,9 MPa (Fig. 9a). Furthermore, the reference Area $A_{0}$ is $5027 \mathrm{~mm}^{2}$ (area within the load ring) as the relative stress differences are lower than $1 \%$ (Fig. 8) and thus the orientation of the flaws is considered to have no influence.

\subsection{Biaxially curved glass}

In contrast to spherically curved glass, the stress distributions are no longer rotationally symmetrical for biaxially curved glass. Figure 10 shows the stress profile of the maximum principal tensile stress $\sigma_{1}$ on the lower surface of the specimen with a geometry of $R_{\mathrm{x}}=2000 \mathrm{~mm}$ and $R_{\mathrm{y}}=10000 \mathrm{~mm}$ and an applied load of $3232 \mathrm{kN}$. It can be seen, that no homogeneous equibiaxial state of stress within the load ring is generated. In Fig. 11, the maximum principal stresses along the $\mathrm{x}$-axis and the $\mathrm{y}$-axis are shown for an increasing load. Here the radii of the specimen are $R_{\mathrm{x}}=4000 \mathrm{~mm}$ and $R_{\mathrm{y}}=8000 \mathrm{~mm}$. The differences of the stress profiles for the two directions can be identified easily: In xdirection, which is the direction with the smaller radius, the stress above the support ring already increases at low loads. In y-direction, an opposite behaviour can be seen, as the highest stress value occurs in the centre of the specimen. Due to increasing of the load, the specimen is pressed to the test setup, which results 

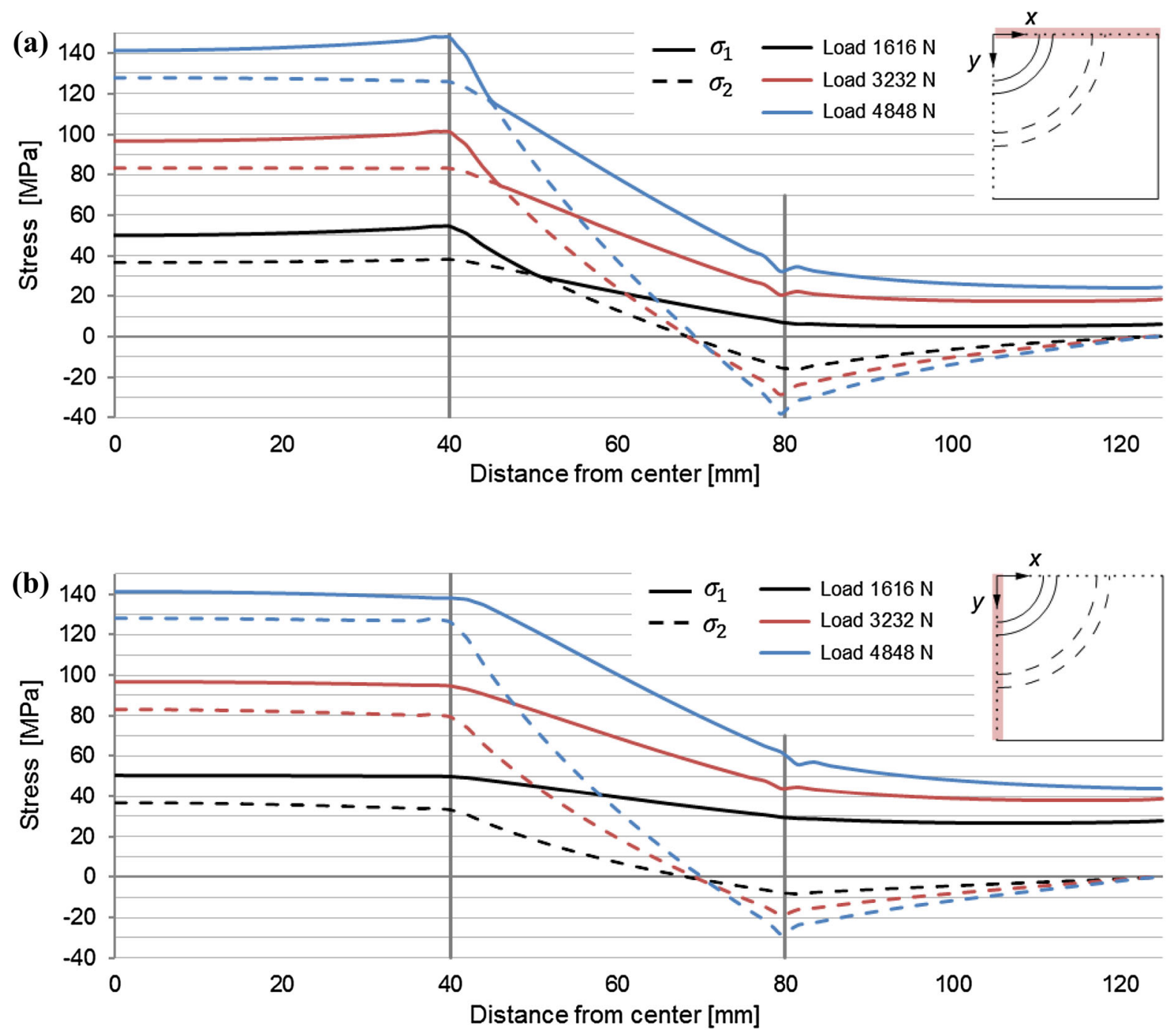

Fig. 11 Principal stresses $\sigma_{1}$ and $\sigma_{2}$ for different load levels, (a) along the x-axis, (b) along the $\mathrm{y}$-axis, $R_{\mathrm{x}}=4000 \mathrm{~mm}, R_{\mathrm{y}}=8000 \mathrm{~mm}$, thickness of glass $t=4 \mathrm{~mm}$

in a slightly more homogeneous stress distribution. However, under further loading, geometric non-linear effects lead to higher stresses above the load ring in comparison to the centre. It can be clearly seen that the differences between the two principal stresses remain at a similar level irrespective of the load level. Thus, even for biaxially curved glass, a uniform stress state can only be achieved for certain load levels.

As with spherically curved glass, a parameter study was carried out using Eq. (5) for a more accurate examination of the stress differences $\Delta \sigma$ within the load ring. Thus, all stress differences between the two principal stresses relative to each other as well as the differ- ences in the stress distribution within the load ring are firstly considered. The results of this parameter study are shown in Fig. 12 for different combinations of the dimensions of the two radii in dependence of the average stress which was calculated with the minimum and maximum principal tensile stress values. It turns out that even for very large radii and slight differences between the two radii $R_{\mathrm{x}}$ and $R_{\mathrm{y}}$, the stress differences within the load ring are very high. A statistically meaningful evaluation with a defined reference area is not possible here.

If the orientation of the flaws is assumed as random, then only the maximum principal tensile stress 
Fig. 12 Relative stress differences $\Delta \sigma$ as a function of different ratios of the radii and average stress, evaluated according to Eq. (5)
Fig. 13 Relative stress differences $\Delta \sigma$ as a function of different ratios of the radii and average stress, evaluated according to Eq. (6)


can be taken into consideration for a statistical evaluation. However, the probability that the greatest microcrack is loaded perpendicular to the flanks within the load ring is reduced. Thus, for a test series, the statistical evaluation results in a larger scattering compared to a test series on flat glass in which the principal stresses are equal. Therefore, only the maximum principal tensile stress is considered for further examination and the relative stress differences $\Delta \sigma$ are determined according to Eq. (6). The results are shown in Fig. 13. The relative stress differences are still high, however, for small differences of the both radii the differences are reaching acceptable values. Considering for example a ratio of $10 / 9$ of the two radii the relative stress differences for a maximum principal tensile stress of $120 \mathrm{MPa}$ are lower than $3 \%$. If the difference of both radii decreases, the relative stress difference also decreases, whereby the results approximate to the investigations of spherically curved glass.

$$
\Delta \sigma=1-\frac{\min \left(\sigma_{1}(r, \varphi)\right)}{\max \left(\sigma_{1}(r, \varphi)\right)} \text { with } 0 \leq r \leq r_{1}
$$

For the investigation of the geometrically non-linear behaviour, the load was increased for different combinations of the radii $R_{\mathrm{x}}$ and $R_{\mathrm{y}}$, and the corresponding stress $\sigma_{1}$ and the deflection $w$ was evaluated in the center of the specimen. Fig. 14 shows the results for the ratio 10/9 of the two radii for three different values of $R_{\mathrm{y}}$. It can be observed that the non-linear behaviour occurs only at loads which result in stress levels well above the typical strength of annealed float glass. Therefore, the analytical solution for the tensile stress is very suitable for large radii. For the deflection, non-linear behaviour can be noticed for smaller loads in comparison to the stress reaction. Furthermore, the non-linear behaviour of the deflection increases for higher radii. This is because the influence of membrane effects due to deflection occurs earlier. For smaller radii, non-linear effects have to be taken into consid- 

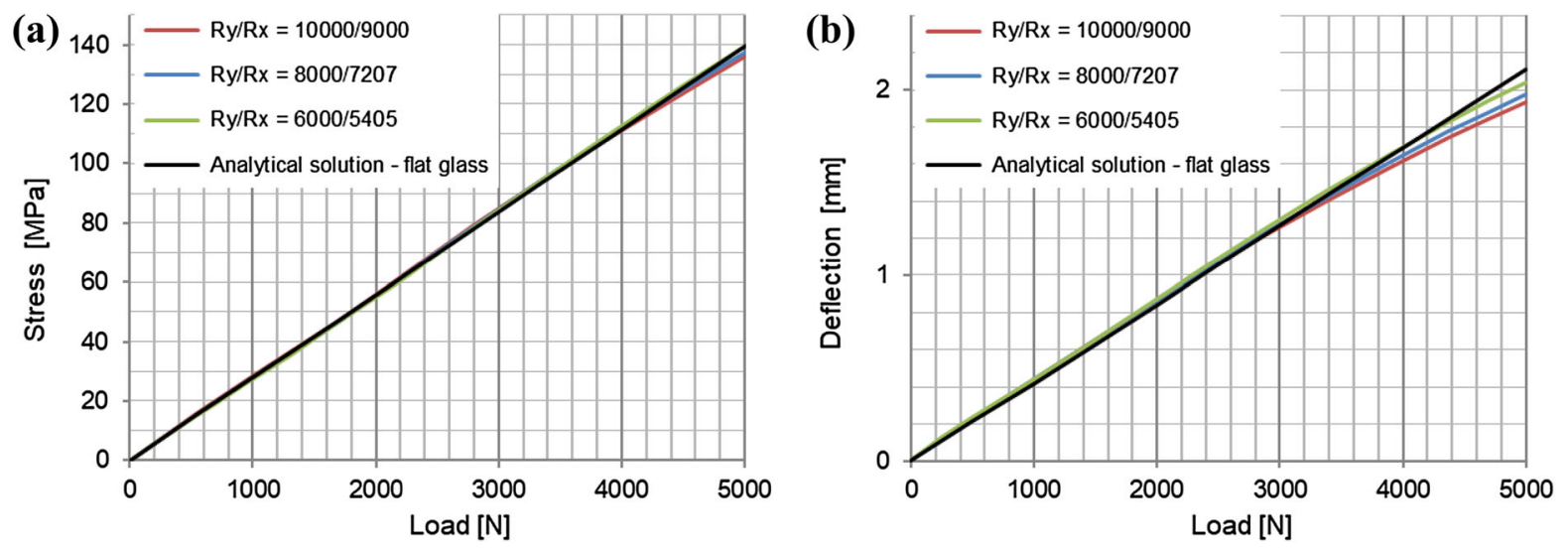

Fig. 14 Maximal principal tensile stress $\sigma_{1}$ (a) and deflection $w(\mathbf{b})$ in the centre of the specimen as a function of the applied load for different radii, biaxially curved glass, thickness of glass $t=4 \mathrm{~mm}$

eration, comparable to spherically curved glass (see Fig. 9).

\section{Conclusion}

The tensile strength of spherically or biaxially curved glass can be examined using the coaxial double ring test for specific thickness-to-radius relations and CDR geometries.

For the investigations on biaxially curved glass, an experimental setup of the double-ring bending test with a diameter of the load ring of $80 \mathrm{~mm}$, a diameter of the support ring of $160 \mathrm{~mm}$ and a square sample with the edge length of $250 \mathrm{~mm}$ was chosen. The thickness of the glass plate was set to $4 \mathrm{~mm}$ as this represents a common glass thickness. With these dimensions of the test setup, geometrically non-linear effects only have to be taken into consideration when applying high loads, which lead to higher stresses than $140 \mathrm{MPa}$. In a first step, spherically curved glass was investigated. The advantage of this geometry is its rotational symmetry leading to a symmetrical tensile stress distribution. It was shown that spherically curved glass with radii larger than $3000 \mathrm{~mm}$ can be examined with this test setup. The generated stress field within the load ring shows differences lower than $2 \%$ for a load range of 40 to $125 \mathrm{MPa}$. In the case of biaxially curved glass, it is shown that, for small differences between the two radii, the differences of the maximum principal tensile stress are sufficiently small, thus the results can be related to a reference area.
Further investigations could be carried out in order to use an effective area which is representative for the applied stress distribution, thus the difference of the two principal stresses can be taken into consideration for the statistical evaluation. Furthermore, the use of smaller radii of the support and load rings could be investigated. The disadvantage here is the higher scattering of the test results since the probability that very large flaws occur on the surface within the load ring decreases. This leads to smaller 5\% fractile values in the statistical evaluation.

A transfer to glass thicknesses which differ from the $4 \mathrm{~mm}$ examined here is possible with further studies as the basic mechanical behaviour remains the same. In the case of thinner glass plates, the geometrically nonlinear effects increase, and in the case of thicker glass plates, these effects decrease. However, thinner glass plates adapt better to the test device and vice versa.

\section{Compliance with ethical standards}

Conflicts of interest The authors declare that they have no conflict of interest

\section{References}

Beason, W., Morgan, J.: Glass failure prediction model. J. Struct. Eng. ASCE 110(2), 197-212 (1984)

Bundesverband Flachglas: Leitfaden für thermisch gebogenes Glas im Bauwesen, BF-Merkblatt 009/2011 (2011)

EN 1288-1:2000: Glass in building. Determination of the bending strength of glass. Fundamentals of testing glass (2000)

EN 572-1:2012: Glass in building-Basic soda lime silicate glass products-Part 1: Definitions and general physical and mechanical properties (2012) 
Ensslen, F., Schneider, J., Schula, S.: Produktion, Eigenschaften und Tragverhalten von thermisch gebogenen Floatgläsern für das Bauwesen - Erstprüfung und werkseigene Produktionskontrolle im Rahmen des Zulassungsverfahrens, Stahlbau Spezial 2010 - Konstruktiver Glasbau (2010), doi:10.1002/stab.201001304

Gulati, S., Helfinstine, J., Roe, T., Khaleel, M. et al.: Measurement of Biaxial Strength of New vs. Used Windshields, SAE Technical Paper 2000-01-2721 (2000), doi:10.4271/ 2000-01-2721

Overend, M.: Recent developments in design methods for glass structures. Struct. Eng. 88(14), 18-26 (2010)
Pećanac, G., Bause, T., Malzbender, J.: Ring-on-ring testing of thin, curved bi-layered materials. J. Eur. Ceram. Soc. 31, 2037-2042 (2011)

Pisano, G., Royer-Carfagni, G.: Towards a new standardized configuration for the coaxial double test for float glass. Eng. Struct. 119, 149-163 (2015)

Schneider, J., Kuntsche, J.K., Schula, S., Schneider, F., Wörner, J.-D.: Glasbau Grundlagen, Berechnung, Konstruktion. Springer, Berlin (2016) 